Provided by the author(s) and University of Galway in accordance with publisher policies. Please cite the published version when available.

\begin{tabular}{|c|l|}
\hline Title & Postponing Maternity in Ireland \\
\hline Author(s) & O'Donoghue, Cathal; O'Shea, Eamon \\
\hline $\begin{array}{c}\text { Publication } \\
\text { Date }\end{array}$ & 2004 \\
\hline $\begin{array}{c}\text { Publication } \\
\text { Information }\end{array}$ & $\begin{array}{l}\text { O'Shea, E., \& O'Donoghue C., (2004) "Postponing Maternity in } \\
\text { National University of Ireland, Galway. }\end{array}$ \\
\hline $\begin{array}{c}\text { Publisher } \\
\text { National University of Ireland, Galway }\end{array}$ \\
\hline Item record & http://hdl.handle.net/10379/1035 \\
\hline
\end{tabular}

Downloaded 2023-04-26T10:24:02Z

Some rights reserved. For more information, please see the item record link above. 


\title{
Postponing Maternity in Ireland
}

\author{
Cathal O'Donoghue* and Eamon O'Shea**
}

Working Paper No. 76

May 2004

Department of Economics

National University of Ireland, Galway

http://www.economics.nuigalway.ie/index/html

\footnotetext{
* Department of Economics, National University of Ireland, Galway; ICER and IZA

** Department of Economics, National University of Ireland, Galway
} 


\begin{abstract}
As in many other developed countries, Ireland in recent decades has experienced a postponement of maternity. In this paper we consider the main trends in this phenomenon, considering changes in first and later births separately. We adapt the theoretical model due to Walker (1995) to incorporate a declining marginal return to experience to provide a human capital/career planning explanation for this postponement. We estimate a hazard model based upon the 1994 Living in Ireland Survey to empirically test this model. The career-planning hypothesis was found to hold. However an assumption about perfect capital markets failed indicating the impact of an income effect on the timing of maternity. The model also identified the importance of cohort differences in the timing of marriage in explaining much of the inter-cohort specific differences in the timing of maternity.
\end{abstract}

Key words: demography trends, fertility

\title{
JEL Classification:
}




\section{Introduction}

Although Ireland has traditionally been categorized as a high fertility country, in recent decades there has been a large decline in the fertility rate. In 1965, the total fertility rate (TFR), in Ireland was about 4 compared with an EU15 average of about 2.7 (Eurostat, 2002). In the last number of decades, as in most other western countries, the birth rate has fallen in Ireland, so that the TFR by 1995 was 1.82 , rising slightly over the remainder of the last decade to 1.98 in 2000. In O'Donoghue and O'Shea (2003b), we described the factors influencing fertility rate by birth order. Part of the explanation for the birth decline has been a delay in maternity. In this paper we consider this issue in more detail.

Table 1: Period and Cohort Fertility Statistics for Ireland

\begin{tabular}{lllllllll}
\hline Period & 1965 & 1970 & 1975 & 1980 & 1985 & 1990 & 1995 & 2000 \\
Mean Age At First Birth & & & 25.5 & 25.5 & 26.1 & 26.6 & 27.3 & 27.8 \\
\% of First Order Births & 23.5 & 27.2 & 30.7 & 29.2 & 29.7 & 33.4 & 36.4 & 40.8 \\
\% of Second Order Births & 19.2 & 21.5 & 24.4 & 24.4 & 25.9 & 27.8 & 30.1 & 30.1 \\
\% of Third Order Births & 16.1 & 16.5 & 17.3 & 19.3 & 18.8 & 18.6 & 18.2 & 17.4 \\
\% of Fourth Order Births & 41.1 & 34.8 & 27.7 & 27.2 & 25.6 & 20.1 & 15.2 & 11.7 \\
TFR (Ireland) & 4.03 & 3.93 & 3.40 & 3.23 & 2.47 & 2.11 & 1.84 & 1.98 \\
TFR (EU-15) & 2.72 & 2.38 & 1.96 & 1.82 & 1.60 & 1.57 & 1.42 & 1.47 \\
Births Outside Marriage & 2.2 & 2.7 & 3.7 & 5.0 & 8.5 & 14.6 & 22.3 & 31.2 \\
& & & & & & & & \\
Birth Cohort & & & 1935 & 1940 & 1945 & 1950 & 1955 & 1960 \\
Completed Fertility & & & 3.4 & 3.3 & 3.3 & 3.0 & 2.7 & 2.4 \\
Mean Age At First Birth & & & & 25.3 & 24.9 & 24.8 & 25.1 & 25.8 \\
\% Childless & & & 4.0 & 5.0 & 6.0 & 9.0 & 13.0 & 15.0 \\
\% With Number of Children: 1 & & & 18.0 & 15.0 & 12.0 & 13.0 & 9.0 & 11.0 \\
\% With Number of Children: 2 & & & 10.0 & 14.0 & 17.0 & 19.0 & 22.0 & 27.0 \\
\% With Number of Children: 3 & & & 21.0 & 23.0 & 26.0 & 27.0 & 27.0 & 26.0 \\
\% With Number of Children: 4+ & & & 47.0 & 43.0 & 40.0 & 34.0 & 28.0 & 22.0 \\
\hline
\end{tabular}

Source: European Social Statistics; Demography (Eurostat, 2002)

In Table 1 we describe some of the main demographic trends in fertility between 1965 and 2000. We notice that the mean age at first birth has risen from 25.2 in 1975 to 27.8 in 2000. Comparing period with cohort effects, we see the earlier decline in mean age at first birth to a low of below 25 for the cohort born 1945-55 before rising for later cohorts. However the rise highlighted by the period effect has been recent and so it has not been captured in the cohort effect yet. While delaying first births, families have also been reducing their total number of births; accounting for less than $43 \%$ of births in 1965, first and second births have risen to over 71 per cent in 2000. In 1965 over $40 \%$ of births were fourth or later children (in fact one third were fifth order or higher), while by 2000 this accounted only for about $12 \%$ of births. 
While the overall decline in the fertility rate (from a TFR of 4.03 in 1965 to 1.42 in 1995) has resulted in a fall in the fertility rate across all age groups (See the age specific fertility rates in Figure 1), the postponement of maternity has seen the fertility rate of older age groups overtake the fertility rate of younger age groups. By the mid-1990's the 30-34 age group had taken over as the age group with the highest fertility rate from the 25-29 age group. The fertility rate of the 35-39 age-group has also surpassed that of the 20-24 age group.

\section{Figure 1: Age-Specific Fertility Rate 1965-94}

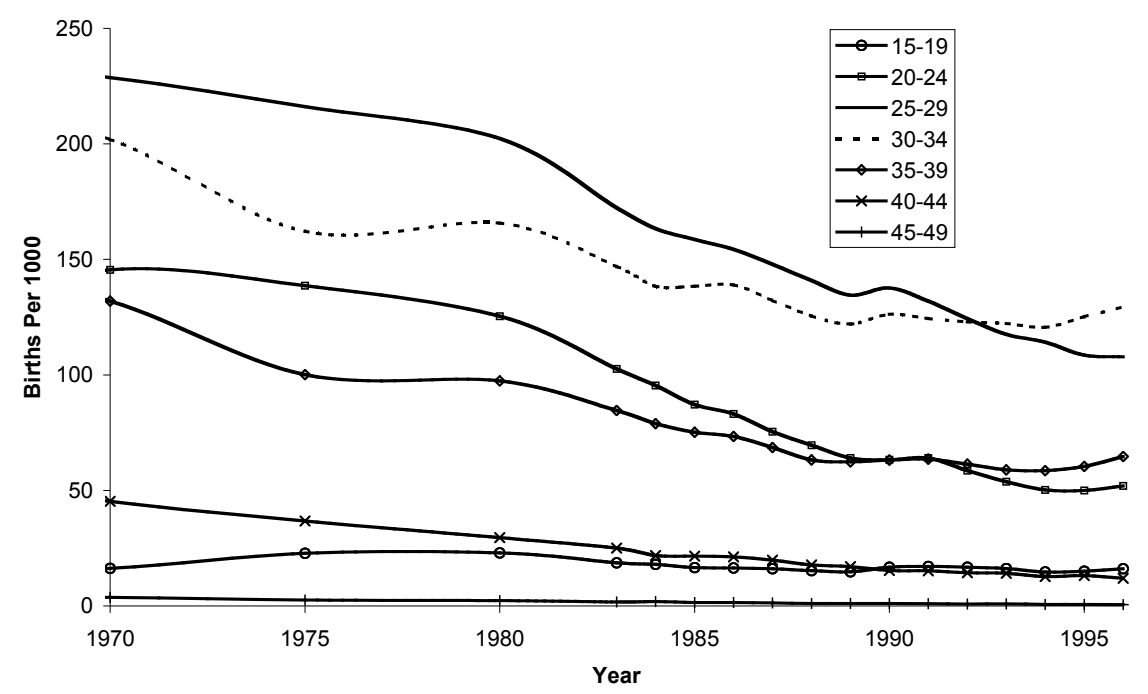

Source: Recent Demographic Developments in Europe, Council of Europe (1997).

As outlined in O'Donoghue and O'Shea (2003a), other than the impact of progressive taxation on human capital accumulation, the tax-benefit policy environment in Ireland is unlikely to have a strong effect on birth decisions as child related policy is quite limited. The policy reform with the likelihood of having the strongest effect has been the belated liberalization of contraceptive laws. Until the 1973 Supreme Court judgment, the use of artificial contraception methods was illegal. This judgment ruled that the importation of contraceptives for personal use was legal. The 1979 Family Planning Act made contraceptives available on prescription through pharmacists and the 1985 Act removed the requirement to seek authorization from doctors. In 1993, remaining restrictions on their sale were removed. Abortion remains illegal in Ireland, however significant numbers travel to the UK for this procedure. The liberalization of the contraceptive laws in Ireland during the 1980 's, allowing fertility to be controlled more and thus facilitating fertility to be delayed.

The period since Ireland joined the European Union in the early 1970's has seen large economic changes. While the late 1990's have seen high growth rates, much of the period of under analysis (1970-1994) has occurred during 
periods of high unemployment. The male unemployment rate (see Figure 2c) rose from about $6 \%$ in the early 1970 s to a peak in $19 \%$ in the mid 1980 's falling during the 1990 's to $4 \%$ in 2000 . The upward trend in unemployment coincided with the start of the postponement of maternity in the early 1980's (Figure 2a). This corresponds with Ahn and Mira's (1999) finding of procyclical fertility. Unemployment has in part been concentrated amongst young workers (15-24) who have had in the period an unemployment rate of about $50 \%$ higher than the average. This is likely to have influenced marriage and fertility decisions, delaying the fertility of the 20 to 30 age group.

\section{Figure 2: Mean Age at Birth, Education Level and Labor Force} Characteristics in Ireland, 1970-2001

(a) Mean Age at First Birth 1975-2001

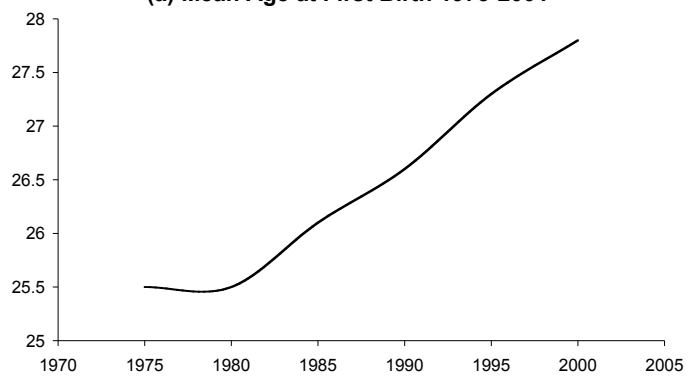

(c) Male Unemployment Rate 1971-2001

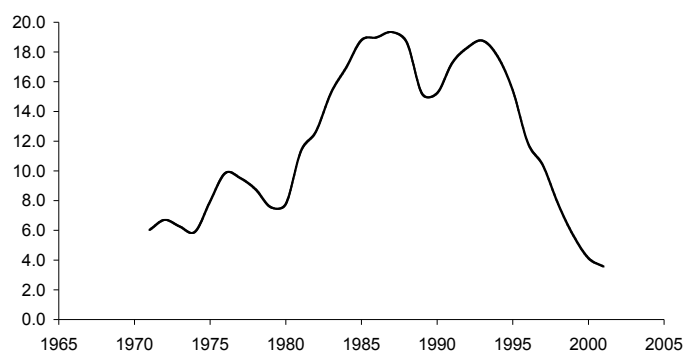

(b) Education Level of Women 1970-1994

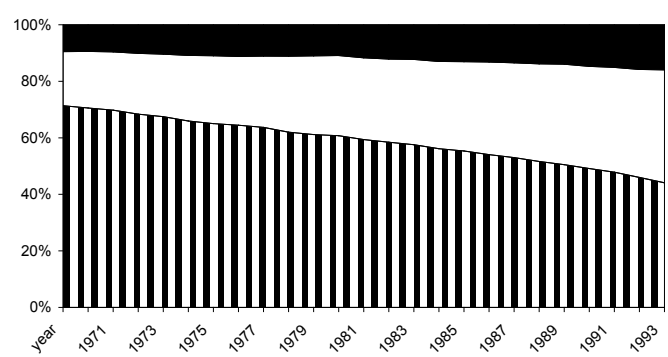

(d) Female Labour Participation Rate 1971-2001

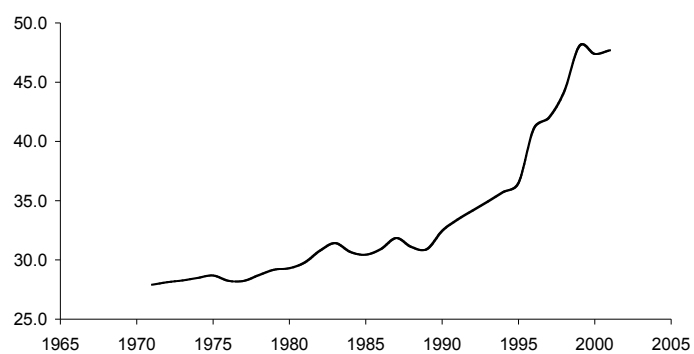

Sources: European Social Statistics: Demography (Eurostat, 2002); Author's Calculations;.and (d) Statistical Yearbook (CSO: 1975-1997), The Trend of Employment and Unemployment (CSO: 1979-1988), Statistical Bulletin (CSO: 1979-2002), Labour Force Survey (CSO: 1979-2001). 
At the same time as the rise in unemployment rates, education levels have been rising (See Figure 2b), resulting in an increase in the age leaving education from about 16 for women born in 1940's to 18 for those born in the early 1970's. Rising education levels tend to delay fertility for reasons outlined in the next section.

Table 2: Mean Age of Mothers at First Birth by Time Period in which First Child was Born in Ireland, Britain, Germany, The Netherlands and Sweden

\begin{tabular}{|c|c|c|c|c|c|c|}
\hline & \multicolumn{6}{|c|}{ Time period in which first child was born } \\
\hline & 1950 ’s & 1960’s & 1970’s & 1980’s & 1990’s & Total \\
\hline \multicolumn{7}{|l|}{ Ireland } \\
\hline Low & 25.9 & 26.1 & 25.2 & 24.6 & 25.5 & 25.5 \\
\hline Medium & 26.5 & 27.1 & 26.3 & 26.2 & 27.3 & 26.6 \\
\hline High & * & 28.0 & 27.2 & 27.9 & 28.7 & 27.8 \\
\hline Total & 26.0 & 26.4 & 25.6 & 25.6 & 26.9 & 26.0 \\
\hline \multicolumn{7}{|l|}{ Britain } \\
\hline Low & 24.7 & 23.9 & 23.8 & 23.6 & 24.2 & 24.0 \\
\hline Medium & 26.2 & 23.5 & 24.4 & 25.5 & 25.5 & 25.0 \\
\hline High & 26.5 & 24.8 & 26.0 & 27.1 & 29.2 & 26.6 \\
\hline Total & 24.9 & 23.9 & 24.2 & 24.5 & 25.4 & 24.5 \\
\hline \multicolumn{7}{|c|}{$\begin{array}{l}\text { Germany } \\
\text { (West) }\end{array}$} \\
\hline Low & 25.2 & 23.9 & 23.3 & 24.9 & 26.4 & 24.6 \\
\hline Medium & 28.0 & 25.3 & 25.2 & 28.2 & 29.2 & 27.5 \\
\hline High & 26.2 & 25.8 & 27.5 & 28.0 & 29.8 & 28.1 \\
\hline Total & 25.5 & 24.0 & 23.8 & 25.6 & 27.3 & 25.1 \\
\hline \multicolumn{7}{|c|}{$\begin{array}{l}\text { Germany } \\
\text { (East) }\end{array}$} \\
\hline Low & 22.5 & 22.3 & 22.0 & 22.2 & 23.3 & 22.3 \\
\hline Medium & 23.1 & 22.0 & 23.1 & 23.2 & 23.8 & 23.0 \\
\hline High & $*$ & 25.6 & 23.1 & 24.8 & 26.0 & 24.5 \\
\hline Total & 23.2 & 22.7 & 22.4 & 22.9 & 23.8 & 22.8 \\
\hline \multicolumn{7}{|c|}{ Netherlands } \\
\hline Low & 23.1 & 24.5 & 24.7 & 25.6 & 26.6 & 24.9 \\
\hline Medium & $*$ & 25.3 & 25.0 & 25.7 & 28.0 & 26.1 \\
\hline High & $*$ & 25.8 & 27.3 & 28.5 & 30.7 & 28.3 \\
\hline Total & 23.2 & 24.7 & 25.0 & 26.0 & 28.0 & 25.5 \\
\hline \multicolumn{7}{|l|}{ Sweden } \\
\hline Low & 24.7 & 23.7 & 24.2 & 24.4 & 25.5 & 24.3 \\
\hline Medium & 25.6 & 23.6 & 24.3 & 25.6 & 26.1 & 24.9 \\
\hline High & 24.7 & 24.6 & 25.7 & 28.2 & 29.8 & 26.8 \\
\hline Total & 24.8 & 23.8 & 24.5 & 25.7 & 27.0 & 24.8 \\
\hline
\end{tabular}

Source: Gustafsson et al, (2002) and Authors' Calculations (Ireland) - Living in Ireland Survey (1994). Notes.

* Small sample size

In Table 2 we decompose the trend in mean age at first birth by education level as reported in the Living in Ireland Survey 1994. The average age at first 
birth as calculated compares well with that calculated using official statistics. Putting the Irish trend in an international context we compare with results contained in Gustafsson et al, (2001) study of the postponement of maternity in Britain, Germany, the Netherlands and Sweden. In this table low education refers to lower secondary or lower levels of education (Junior Certificate in Ireland), medium education refers to high school diploma level (Leaving Certificate in Ireland and high education refers to tertiary level education.

Overall the trend in Ireland follows the U-shaped pattern found in the other countries. Average age at first birth in the 1950's and 1960's fell to a low point in the 1970's and 1980's before rising in the 1990's. Typically the average age increases with education level. Those with high education had the biggest average postponement in maternity between the 1970's and 1990's. The lowest average age at first birth occurred for those with high education in the 1970's, while the lowest point occurred for lower and medium educated women in the 1980's. This pattern follows in part the trend in age at marriage, which historically has been high by international standards (Coleman, 1992), having fallen in the 1970's and has risen subsequently. This trend occurred slightly later in Ireland than in the other countries considered where the low points occurred in the 1960's in Britain and Sweden, the 1970's in East and West Germany and have risen since the 1950's in the Netherlands.

However although the pattern of delayed maternity is similar in Ireland, the level is higher. Until the 1980's average age at first birth in Ireland was higher than in the other countries, being surpassed at this point by the Netherlands and in the 1990's by Western Germany. The average age at first birth remained lower in the other countries. In general this is a pattern replicated for low and medium education levels, however for high education levels from the 1980's Ireland had a lower average age at first birth than for all countries except East Germany.

In Table 3 we report the mean age of later births in Ireland. The trends are similar to first births with again a U-shaped pattern with a low point in the 1970's for high educated women and the 1980's for low and medium educated women. The average gap between first and second and second and third births for all education levels and across time has risen gradually over time from a gap of about 1.5 years in the 1950's to an average gap of about 2.5 years in the 1990's. The gap between third and fourth births has fallen to some extent. This is partly a selection issue as the proportion having fourth births has fallen. Nevertheless much of the driving force in the increasing average age is due to the knock on effect of later earlier births.

In this paper we will now go on to consider the factors that have influenced the postponement of maternity over the period 1970-1994. In the next section, we consider the theoretical background to economic explanations of duration to first birth and later births. Section 3 describes the data used. In section 4 we report a descriptive analysis of differential duration to births and in section 5 , we estimate empirical models of duration to birth. In section 6 , utilizing the empirical models estimated in section 5 , we consider the driving factors behind the delay in fertility. Section 7 concludes. 
Table 3: Mean Age of Mothers at Second, Third and Later Birth by Time Period in which First Child was Born in Ireland

\begin{tabular}{lllllll}
\hline \multicolumn{6}{c}{ Time period in which second, third and later children was born } \\
\hline \multirow{2}{*}{ First Birth } & 1950 's & 1960 's & 1970 's & 1980 's & 1990 's & Total \\
Low & & & & & & \\
Medium & 25.9 & 26.1 & 25.2 & 24.6 & 25.5 & 25.5 \\
High & 26.5 & 27.1 & 26.3 & 26.2 & 27.3 & 26.6 \\
Total & $*$ & 28.0 & 27.2 & 27.9 & 28.7 & 27.8 \\
Second Birth & 26.0 & 26.4 & 25.6 & 25.6 & 26.9 & 26.0 \\
Low & & & & & & \\
Medium & 27.3 & 27.8 & 27.6 & 27.5 & 28.2 & 27.6 \\
High & 28.2 & 29.2 & 28.6 & 28.6 & 30.2 & 29.0 \\
Total & $*$ & 30.2 & 29.3 & 30.4 & 31.5 & 30.1 \\
Third Birth & 27.4 & 28.2 & 27.9 & 28.2 & 29.7 & 28.2 \\
Low & & & & & & \\
Medium & 28.3 & 29.7 & 30.1 & 30.3 & 30.5 & 29.9 \\
High & 31.2 & 31.3 & 31.3 & 31.1 & 32.5 & 31.5 \\
Total & $*$ & 31.9 & 31.5 & 32.8 & 33.1 & 32.3 \\
Fourth Births & 28.7 & 30.1 & 30.4 & 30.8 & 31.7 & 30.4 \\
Low & & & & & & \\
Medium & 29.3 & 31.8 & 32.2 & 32.6 & 32.4 & 31.9 \\
High & 31.0 & 33.6 & 33.9 & 32.9 & 33.5 & 33.4 \\
Total & $*$ & 34.3 & 34.2 & 34.7 & 34.3 & 34.3 \\
\hline Source: Auth & 29.5 & 32.1 & 32.7 & 32.8 & 33.1 & 32.3 \\
\hline
\end{tabular}

Source: Authors' Calculations - Living in Ireland Survey (1994).

Notes.

* Small sample Size

\section{The Model}

As we saw above, the average age at first birth has increased in Ireland. Here we consider some of the reasons provided by economic theory for these changes. Gustafsson, (2002) cite two principle reasons given by Hotz et al., (1997) for the general postponement of first birth in Western countries; the consumption smoothing and women's career planning motives. The consumption-smoothing motive relates to having enough resources to afford having a child, while the career-planning motive refers to the need to have the time for child caring and rearing.

Greater education participation can cause a delay in births because being in education can be incompatible with having children, for financial and lifestyle reasons. Moreover, after leaving education, highly educated women are likely to spend more time in investment in job search and in finding the right job. There is also a positive correlation between investment in schooling and investment in on the job training, both of which combine to provide higher wages for educated women (Gustafsson, 2001). This results in those with higher education levels tending to have higher growth in earnings in the years 
immediately following education. Therefore more highly educated women may wish to delay having a child until a stable and desired career pattern has been established. A third reason for career planning delaying maternity described by Gustafsson et al. is attitude. For example a low educated woman may try to fit market work around family responsibilities, while more educated women may try to have children when lower labour supply such as a maternity break or part-time work will have least effect on her career.

The opportunity cost of having children and caring for them is, therefore, is also higher for educated women, both in the short-term and in the long-term. Consequently, increased education is an important factor contributing to the postponement of maternity. Countries with marked increases in higher education tend to be highly correlated with the countries having the most pronounced delays in the mean age at first birth. (Kohler et al, 2002).

Fertility is a dynamic process over the life-course and, as such, is best examined within the framework of dynamic, sequential theories of life-cycle fertility. These theories should include consideration of life-cycle consumption, life-cycle labour supply, human capital accumulation, institutional models and stochastic models of human reproduction (Hotz et al, 1997).

In this paper we utilise a variant of Walker's (1995) model of fertility. Our life-cycle model depends upon the utility from consumption $\left(x_{t}\right)$ and utility from children both from the number of children $\left(n_{t}\right)$ and from the quality of these children $(q)$ at times $\mathrm{t}$ across the lifetime from 0 to $\mathrm{T}$. The number of children $\left(n_{t}\right)$ at time $t$ depends upon the fertility at different points in time. The model assumes no bequest motive and assumes that consumer preferences are inter-temporally and contemporaneously strongly separable. At time $\mathrm{t}$ discounted future utility is:

$$
U_{t}=\sum_{s=t}^{T} \delta_{s}\left[v\left(n_{s} q\right)+u\left(x_{s}\right)\right]
$$

where $\delta_{t}=(1 / 1+r)^{(t-1)}$ is the rate of time preference, $r$ the interest rate and $v()$ and $u()$ are strictly increasing and concave functions.

At each time $t$ the mother has a time endowment scaled to 1 divided into labour market activity $h_{t}$, childcare $f\left(n_{t}\right)$ and schooling $s_{t}$. In this model we assume that either schooling or labour market activity can occur at a particular point but not both. Childcare depends upon the age of each child, where a child at age $j$ requires $\phi^{j}$ proportion of the year of care. Summing over the number of children in a family at time $t$, total childcare demanded is:

$$
f\left(n_{t}\right)=\sum_{j=0}^{M} \phi^{j} b_{t-j}
$$

Hence

$$
1=f\left(n_{t}\right)+h_{t}+s_{t}=\sum_{j=0}^{M} \phi^{j} b_{t-j}+h_{t}+s_{t}
$$

and so 


$$
h_{t}=1-\sum_{j=0}^{M} \phi^{j} b_{t-j}-s_{t}
$$

where $\mathrm{M}$ is the age of adulthood or independence of the child from their parents.

The quality of the child is assumed to depend upon the total monetary expenditure to produce child services $g\left(n_{t} q\right)$ and is defined as the sum of direct expenditures times the quality index $m_{t}^{j} q_{t}$ plus childcare costs $c_{t}^{j}$ (that in turn depend upon the hours worked - both vary with the age of the child $j$ )

$$
g\left(n_{t} q\right)=\sum_{j=0}^{M} m_{t}^{j} q b_{t-j}+\left(h_{t}+s_{t}\right) \sum_{j=0}^{M} c_{t}^{j} b_{t-j}
$$

Total income at time $\mathrm{t}$ is the mother's income from labour $y f_{t}$ and the husband's income from labour $y m_{t}$.

Economic uncertainty provides the incentive to delay decisions that imply long-term commitments such as children and it provides an incentive to invest in education and human capital (Kohler et al 2002). Individuals form expectations about the future on the basis of current information in income and jobs (Bettio and Villa, 1998). Job stability is important in preference formation and lower fertility is likely to follow among generations faced with current poor employment prospects. The experience of unemployment impacts on perceptions of inter-generational relative income (Easterlin, 1980) causing behavioural changes with respect to marriage and childbearing. Evidence from Ahn and Mira (2001) for Spain suggests that unemployment and a lack of stable jobs among young men has forced couples to delay their marriage and childrearing leading to a very low fertility rate in that country. Conversely, a strong labour market is likely to increase both marriage and childbearing with positive effects of male income and male employment on fertility (Hotz and Miller, 1988; Heckman and Walker, 1990). In a comparative analysis of the cyclical component of unemployment rates and fertility rates, Ahn and Mira (2001) found that in 15 out of 21 OECD countries, fertility is strongly procyclical.

We incorporate economic instability in our model through the inclusion of the unemployment rate $u_{t}$ at each time t. Hence, expected male earnings are $y m_{t}\left(1-u_{t}\right)$. As most working age males work full-time in Ireland, we assume that father's work full-time, ignoring labour supply effects. We allow female labour supply $\left(h_{t}\right)$ to vary. Hence total female labour income at time $\mathrm{t}$ is labour supply times the wage rate $\left(w_{t}\right)$ :

$$
y f_{t}=h_{t} w_{t}
$$

The wage rate of the woman (in equation 7) positively depends upon the human capital accumulation $k_{t}$ from on the job experience $\left(h_{t}\right)$ and schooling $\left(s_{t}\right)$ at time $t$, so that both coefficients $\left(\mu_{1}\right.$ and $\left.\mu_{3}\right)$ are positive, and also on the market rental rate of human capital $\omega_{t}$. As the rate of return to experience falls with experience, we incorporate the square of experience with a negative coefficient $\left(\boldsymbol{\mu}_{2}\right)$, to produce the typical age-earnings profile. We incorporate in 
our model, the assumption that human capital depreciates during periods out of the labour force for caring for children, where the coefficient $\left(\mu_{4}\right)$ is negative. ${ }^{1}$

$$
\begin{aligned}
& w_{t}=\omega_{t} k_{t} \\
& =\omega_{t} \cdot \exp \left(\mu_{0}+\mu_{1} \sum_{j=1}^{t-1} h_{j}+\mu_{2}\left(\sum_{j=1}^{t-1} h_{j}\right)^{2}+\mu_{3} \sum_{j=1}^{t-1} s_{j}+\mu_{4} f\left(n_{t}\right)\right),(7) \\
& \mu_{1}, \mu_{3}>0 ; \mu_{2}, \mu_{4}<0
\end{aligned}
$$

Where $p_{t}$ is the price of the composite good $x_{t}$ and $\_t$ is the discount rate the life-cycle budget constraint for the family can be defined $\mathrm{as}^{3}$ :

$$
\sum_{t=1}^{T}\left(p_{t} x_{t}+g\left(n_{t} q\right)\right) \delta_{t}=\sum_{t=1}^{T}\left(y m_{t}+h_{t} w_{t}\right) \delta_{t}
$$

The optimization problem therefore becomes

$$
\underset{b_{t}, x_{t}, q_{t} ; t=1 \ldots T}{\operatorname{Max}} \sum_{t=1}^{T} \delta_{t}\left[v\left(n_{t} q\right)+u\left(x_{t}\right)\right]
$$

subject to the budget constraint

$$
\sum_{t=1}^{T}\left(p_{t} x_{t}+g\left(n_{t} q\right)\right) \delta_{t}=\sum_{t=1}^{T}\left(y m_{t}\left(1-u_{t}\right)+h_{t} w_{t}\right) \delta_{t}
$$

producing the following Lagrangean expression:

$$
\begin{aligned}
& L=\underset{b_{t}, x_{t}, q_{t} ; t=1 \ldots T}{\operatorname{Max}} \sum_{t=1}^{T} \delta_{t}\left[v\left(n_{t} q\right)+u\left(x_{t}\right)\right]- \\
& \lambda\left[\sum_{t=1}^{T}\left(p_{t} x_{t}+g\left(n_{t} q\right)\right) \delta_{t}-\sum_{t=1}^{T}\left(y m_{t}\left(1-u_{t}\right)+h_{t} w_{t}\right) \delta_{t}\right]
\end{aligned}
$$

Expanding using (4), (5) and (7) we get the

$$
\begin{aligned}
& L=\operatorname{Max}_{b_{t}, x_{t}, q_{t} ; t=1 \ldots T} \sum_{t=1}^{T} \delta_{t}\left[v\left(n_{t} q\right)+u\left(x_{t}\right)\right]- \\
& \lambda\left[\begin{array}{l}
\sum_{t=1}^{T}\left(p_{t} x_{t}+\sum_{j=0}^{M} m_{t}^{j} q b_{t-j}+\left(1-\sum_{j=0}^{M} \phi^{j} b_{t-j}\right) \sum_{j=0}^{M} c_{t}^{j} b_{t-j}\right) \delta_{t}- \\
\sum_{t=1}^{T}\left(y m_{t}\left(1-u_{t}\right)+\left(1-\sum_{j=0}^{M} \phi^{j} b_{t-j}-s_{t}\right) \omega_{t} \cdot k_{t}\right) \delta_{t}
\end{array}\right]
\end{aligned}
$$

where

$$
k_{t}=\exp \left(\begin{array}{l}
\mu_{0}+\mu_{1} \sum_{j=1}^{t-1}\left(1-\sum_{j=0}^{M} \phi^{j} b_{t-j}-s_{j}\right)+ \\
\left.\mu_{j=1}^{t-1}\left(1-\sum_{j=0}^{M} \phi^{j} b_{t-j}-s_{j}\right)\right)^{2}+ \\
\mu_{3} \sum_{j=1}^{t-1}\left(s_{j}\right)+\mu_{4}\left(\sum_{j=0}^{M} \phi^{j} b_{t-j}\right)
\end{array}\right)
$$

The first order conditions are 


$$
\begin{aligned}
& \frac{\delta L}{\delta x_{t}}=\frac{\delta U}{\delta x_{t}}-\lambda p_{t} \delta_{t}= \\
& \beta^{t-1} u^{\prime}\left(x_{t}\right)-\lambda p_{t} \delta_{t}=0 \\
& \frac{\delta L}{\delta b_{t}}=\frac{\delta U}{\delta b_{t}}-\lambda \pi_{t}(q)= \\
& \sum_{j=t}^{T} \delta_{j} v^{\prime}\left(n_{j} q\right) q-\lambda \pi_{t}(q)=0 \\
& \frac{\delta L}{\delta q}=\frac{\delta U}{\delta q}-\lambda \sum_{j=t}^{T}\left[\sum_{k=0}^{M} m_{j}^{k} b_{j-k} \delta_{j}\right] \\
& =\left(\begin{array}{l}
\sum_{j=t}^{T} \delta_{j} v^{\prime}\left(n_{j} q\right) n_{j}- \\
\left.\lambda \sum_{j=t}^{T}\left[\sum_{k=0}^{M} m_{j}^{k} b_{j-k} \delta_{j}\right]\right)=0
\end{array}\right.
\end{aligned}
$$

where $\lambda$ is the Lagrangean multiplier associated with the lifetime budget constraint, or the marginal utility of wealth and $v^{\prime}()$ is the derivative of $v()$ with respect to $n_{t} q . \pi_{t}$ is the full present value of a childbearing in period $\mathrm{t}$ and is defined as:

$$
\begin{aligned}
& \pi_{t}(q)=\sum_{k=t}^{T} m_{k}^{k-t} q \delta_{k}+\sum_{k=t}^{T} h_{k} c_{k}^{k-t} \delta_{k}-\sum_{k=t}^{T} \phi^{k-t} \delta_{k} \sum_{l=0}^{M} c_{t}^{l} b_{t-l} \\
& +\sum_{k=t}^{T} \phi^{k-t} w_{k} \delta_{k}+\sum_{k=t+1}^{T}\left(\left(\mu_{1}-\mu_{4}+2 \mu_{2}\left(\sum_{j=1}^{k-1} h_{j}\right)\right) \sum_{l=0}^{k-t-1} \phi^{l}\right) h_{k} w_{k} \delta_{k}
\end{aligned}
$$

The terms can be described as follows:

- Quality adjusted direct expenditure for the child at different ages until aged M. $\sum_{k=t}^{T} m_{k}^{k-t} q \delta_{k}$

- Direct childcare expenditure for the hours worked by the mother for each of the dependent years. $\sum_{k=t}^{T} h_{k} c_{k}^{k-t} \delta_{k}$

- The reduction in non-parental childcare expenditure for other children due to having more than one child. $\sum_{k=t}^{T} \phi^{k-t} \delta_{k} \sum_{i=0}^{M} c_{t}^{l} b_{t-l}$

- The cost of parental childcare for the child $\sum_{k=t}^{T} \phi^{k-t} w_{k} \delta_{k}$

- The foregone human capital due to rearing the child.

$$
\sum_{k=t+1}^{T}\left(\left(\mu_{1}-\mu_{4}+2 \mu_{2}\left(\sum_{j=1}^{k-1} h_{j}\right)\right) \sum_{l=0}^{k-t-1} \phi^{l}\right) h_{k} w_{k} \delta_{k}
$$

Transforming (12b) we get the following

$$
\sum_{j=t}^{T} \delta_{j} v^{\prime}\left(n_{j} q\right)=\frac{\lambda \pi_{t}(q)}{q}
$$


Defining $V_{t}=\sum_{j=t}^{T} \delta_{j} v^{\prime}\left(n_{j} q\right)$, as in the case of Walker (1995) we can derive an expression describing the inter-temporal substitution effect:

$$
\frac{V_{t+1}}{V_{t}}=\frac{\pi_{t+1}(q)}{\pi_{t}(q)}
$$

This describes how fertility is allocated across the life-cycle, conditional on the pattern of earnings over the life-cycle and upon the quality of child demanded. This expression relates the price a woman is willing to pay to transfer fertility between periods, while the right hand side of the equation is the price available in the market to transfer fertility between years. ${ }^{2}$ Ignoring the wealth effect, the greater this ratio, the greater the opportunity cost of having a child in the future and so births will be had earlier. The steeper the profile of the opportunity cost therefore, the earlier the birth is expected to be.

How do the different terms impact on the decision to have a birth? As per Becker and Lewis (1973), the higher the quality of the child, the higher the shadow price of the child. The demand for child services is regarded as a normal good, and so higher income (say of the father $y m_{t}$ ) will cause demand for child services to increase. Becker (1960) postulates that the income elasticity of quality is likely to be substantially higher than the income elasticity of the number of children. Therefore as family income rises, the demand for quality is likely to increase at a faster rate than quantity and so because higher quality increases the shadow price of a child, there may be a negative relationship between income and number of children. However because quality depends upon a positive quantity, the income elasticity of demand for the first child is likely to be positive and negative for the demand for later children. We must note however that perfect capital markets (PCM) are assumed in the model (See Hotz et al, 1997; Happel et al., 1984 and Gustafsson, 2001). This assumption follows from equation (9), which assumes that the budget constraint balances over the lifetime, implicitly assuming that resources can be saved or borrowed from the future. The model therefore assumes away the consumption-smoothing hypothesis.

Economic models of labour supply behaviour predict that increases in educational attainment and wage rates for women would lead to increases in their labour supply. The impact of the increased labour supply impacts on the shadow price of a child through the second term due to the cost of childcare, increasing the cost of a child (Becker and Lewis, 1973; Willis, 1973). However the existence of more children, through the third term in the shadow price reduces the price, attributed by Del Bono (2001) to positive economies of scale in childcare. Although increased labour supply may increase the cost of child-care, if we assume that childcare costs are constant over time relative to earnings, then this term will have no effect on the substitution effect, but rather will influence fertility decisions through the lifetime income effect. Where capital markets are not perfect, where the ability to borrow is limited, then the cost of child-care may influence the decision of when to have a child. 
There is a positive correlation between investment in schooling and investment in on the job training, further increasing wages for educated women (Gustafsson, 2001) and thus the opportunity cost of having children increases in the short term, the opportunity caring for them (shadow price term 4) and in the long term due to lower human capital (shadow price term 5). As our model assumes that wages increase with experience, the later a birth comes in the life-cycle, the greater the opportunity cost of having a child. This will tend to result in those with higher earnings having a higher opportunity cost of having a child. This relates to Cigno's (1991) model that predicts that those with higher pre-parental human capital will have less children. In Cigno's model, those with higher pre-parental human capital will have children sooner. Pre-parental human capital depends upon two factors, human capital due to experience and human capital due to schooling. In this model what determines the timing of birth is the rate of human capital accumulation. The higher the rate of human capital accumulation, the greater the opportunity cost of rearing a child and the higher pre-parental human capital for women. Those with higher schooling will have more school-based human capital, while those with some experience will have more experience-based human capital. The cost of parental childcare is therefore lower at an earlier age and so there is an incentive to have a child earlier.

However the impact on the timing of a birth due to the opportunity cost of parental childcare is counter-balanced by the future human capital loss due to the parental childcare. If a parent reduces or stops work to care for a child, then future years will have lower human capital. The human capital loss results from a number of factors. (a) The higher the wage rate, the greater the loss; (b) the greater the future labour supply, the greater the loss; (c) the greater the period spent in parental childcare, the greater the loss, due both to the loss of human capital relative to not caring for children $\left(\mu_{1}\right)$ and due to the depreciation of human capital $\left(\mu_{4}\right)$ that occurs during periods out of the labour market. (d) The negative coefficient of experience squared in the wage equation $\left(\boldsymbol{\mu}_{2}\right)$, reduces the per annum loss in human capital as experience increases. These effects however are contained largely in both $\pi_{t}(q)$ and $\pi_{t+1}(q)$, regardless of the timing of the birth and so in themselves do not influence the substitution effect.

What drives the impact of future human capital loss on the substitution effect is the impact of the fact of the later the birth the less time that remains between the time of birth, $t$ and the end of the working life, $T$. Therefore, the later the birth, the lower the cost in terms of human capital loss. If future human capital losses fall at a faster rate than the opportunity cost of parental child-care increases, then the total cost due to both effects will fall over time, producing an incentive to have births later. 


\section{Methodology and Data}

\subsection{Data}

In this paper we utilise the 1994 Living in Ireland Survey, the Irish component of the European Community Household Panel Survey, to investigate the strength of the different forces on fertility trends. The Survey contains substantial cross-section information on employment and demographic characteristics in 1993-1994. The 1994 wave also contained additional retrospective information on fertility, partnership formation, parental history and employment status. The event history data allows us to utilise variables that describe the duration in a number of dimensions; since last birth, marriage, and since leaving education.

O'Donoghue and O'Shea (2003a) compare the validity of the main dependent variables recorded in the survey with similar figures in official statistics published by the Central Statistics Office. Overall the survey captures the decline observed in the official statistics, but the decline is observed to be smoother than the sharp decline observed in official statistics.

In this study, we are interested in the relationship between labour market histories and fertility. It would have been desirable to have historical panel data or at least detailed employment recall event history data. However the retrospective employment history data available is imperfect. Nevertheless in the majority of cases it was possible to identify full histories. For a minority of cases $(8.5 \%$ of women and $3.5 \%$ of their spouses), some imputations were necessary. ${ }^{4}$ For simplification purposes and because recall information is expressed in years, spells have been rounded to nearest year.

In this study we focus on marital births as during the period we are focusing on, non-marital births accounted only for a small proportion of all births. In the original sample of women, we produce a panel data set of 25 years from 1970-1994 comprising a total of 58938 observations for 3235 married women. In the subset of women whose histories we can identify, we have 38803 observations for 3043 married women, while in the subset whose spouse's history we can identify, we have 31027 observations for 2237 married women. ${ }^{5}$

Because of potential error generated through our imputation mechanism in addition to the recall error associated with this type of data, we utilise duration in employment rather than actual employment status at a point in time as an explanatory variable. As this is an aggregate measure, it is likely to be more accurate than current employment status.

\subsection{Cox Proportional Hazards Model}

We use a modelling method based upon survival analysis in this paper. Survival analysis is concerned with modelling the hazard of an event $\mathrm{z}$ at time $\mathrm{t}, \mathrm{h}(\mathrm{t}, \mathrm{z}(\mathrm{t}))$, the probability of an event at time $\mathrm{t}$ having survived until time $\mathrm{t}$. 
We utilise a Cox proportional hazard model (see Kalbfleisch and Prentice, 1980), where the hazard takes the form:

$$
h(t, z(t))=h_{0}(t) \exp (z(t) \beta)=h_{0}(t) \exp \left(\sum_{i} \beta_{i} x_{i}\right)
$$

Here $h_{0}(t)$ represents the baseline hazard at time $\mathrm{t}$, or the hazard function for the mean individual in the sample, $z(t)$ is a vector of time-varying and timeunvarying explanatory variables or covariates, with $\beta$ the estimated parameters.

We utilise this model in turn to estimate the factors that influence the hazard of a first second, third and fourth births. One needs to be cautious about the results of this method as estimating each birth interval separately as outlined in Heckman and Walker (1990), may produce biased estimates. Heckman and Walker use instead a joint approach in order to capture to some extent individual heterogeneity. Individual heterogeneity may represent to some degree individual differences in fecundity or general biological variation. Gustafsson (2001) feels however that in modern European countries, economic variables would be more important than biological factors.

\subsection{Earnings Model}

Fertility levels in our model depend upon female wage rates and male earnings. However as we only observe wage levels in 1994, we need to simulate the history of wages. We regress 1994 wages on 1994 characteristics and then simulate potential wages for each person each year based upon the characteristics of that year. This is unlikely to have a strong effect on results as Heckman and Walker (1990) finds that current wages as the correlation between current and future wages is very high. In work done on Irish data Hynes and O'Donoghue (2003) find that permanent income accounts for about two thirds of all stochastic variability in Irish wages.

In both cases, we use a standard earnings equation to estimate female wage rates and male earnings, utilising the Heckman procedure to account for sample selection bias (Heckman, 1979). In the earnings equation, we use education level and employment experience. The "Heckman" method adjusts the coefficients in the model in order to account for any selection bias associated with the fact that we only observe earnings for those who work. This is done through the use of an extra variable in the earnings equation, known as the inverse Mills ratio _, generated from a (probit) selection equation. We define the inverse Mills ratio as

$$
\lambda=-\frac{\phi(b x)}{\Phi(b x)},
$$

where $\phi(b x)$ is the normal probability density function, $\Phi(b x)$ is the normal cumulative distribution function and $b x$ is the probability value of being in work as predicted from the selection equation. In addition to education and experience, duration of marriage as well as parental and spouse characteristics are used for identification. Because simulated earnings depend upon 1994 
earnings levels, the predicted earnings will only capture changes in earnings levels due to shifts in education and employment patterns and not wealth changes due to productivity gains generally in the economy. We would therefore expect the impact of these variables to be underestimated.

Table 4 reports the main features of the female wage equation. The model has a standard human capital model structure with positive returns to education and an inverted u-shape return to experience. We also include a variable accounting for periods out of the labour market to incorporate the impact of the depreciation of human capital during these periods. The coefficient on this variable is negative and significant.

Table 4: Female Hourly Wage Equation $1994^{1}$

\begin{tabular}{|c|c|c|}
\hline & Coefficient & p-value \\
\hline University Education & 1.024 & 0.000 \\
\hline Upper Secondary Education & 0.529 & 0.000 \\
\hline Lower Secondary Education & 0.247 & 0.004 \\
\hline Years in Work & 0.075 & 0.000 \\
\hline Years in Work ${ }^{2}$ & -0.001 & 0.000 \\
\hline Years out of Work & -0.019 & 0.000 \\
\hline Inverse Mills Ratio & 0.175 & 0.010 \\
\hline Constant & 1.939 & 0.000 \\
\hline No. of obs. & 1128 & \\
\hline Adjusted $\mathrm{R}^{2}$ & 0.405 & \\
\hline
\end{tabular}

Source: Author's Calculations - Living in Ireland Survey, (1994).

\subsection{Shadow Price of a Child}

We now consider the impact of this earnings model on the opportunity cost of having a child. We saw above that if the shadow price of a child is lower, later in life, then birth will be delayed. If we assume that the first three terms of the shadow price are constant across the life-cycle, then because the intertemporal substitution is based upon the ratio of shadow prices, without much loss in generality, we can utilise a simpler model for explanatory purposes:

$$
\pi_{t}(q)=\left(\begin{array}{l}
\sum_{k=t}^{T} \phi^{k-t} w_{k} \delta_{k}+ \\
\sum_{k=t+1}^{T}\left(\left(\mu_{1}-\mu_{4}+2 \mu_{2}\left(\sum_{j=1}^{k-1} h_{j}\right)\right) \sum_{i=0}^{k-t-1} \phi^{l}\right) h_{k} w_{k} \delta_{k}
\end{array}\right)
$$

We now consider a woman who works for her entire lifetime except for a period not participating in the labour market to raise children. Assume that this period amounts to one year at the time of birth. Therefore $\phi^{0}$ is equal to 1 . We assume that earnings grow at the same rate as the discount rate. This means that discounted future wages with growth are the same as undiscounted future wages without growth. Therefore the opportunity cost of parental childcare for 
this period is $w_{t}$ in time t. The loss of human capital due to this year out of the labour market is $\sum_{k=t+1}^{T}\left(\mu_{1}-\mu_{4}+2 \mu_{2} \sum_{j=1}^{k-1} h_{j}\right) w_{k}$.

In figure 3 we illustrate the components of the shadow price of having a child as per equation (13'). Graph (a) plots the earnings profiles of those with lower secondary, upper secondary and university education, where the scale is based upon earnings of a lower secondary educated woman at age 16 being equal to 100. The profiles have the characteristic inverted $u$ shape resulting from the quadratic term in the earnings function. While for particular cohorts, earnings tend to rise over time, albeit at a declining rate, if we assume that the average growth rate is the same as the discount rate, then the discounted cohort specific earnings profile is the same as the cross-sectional age earnings profile.

Discounted earnings represent the opportunity cost of parental childcare. In graph (b) we consider the impact each year of having one year less experience, combined with the corresponding depreciation of human capital due to being out of the labour market. Because of our assumption that women work from the time they leave education until retirement except for the year taken out to care for a child, the experience of a higher educated person is lower at each age. Because of this, the proportional loss in human capital is greater. Therefore, combined with the fact that earnings grow faster for higher educated, the human capital loss due to a period in parental childcare grows at a faster rate for higher educated women. Because the proportional human capital loss falls with experience, the slopes of these curves decline with experience and eventually go negative after the age of 50 .

The total human capital loss is defined in graph (c). For a birth at time t, the total human capital loss is defined as the sum of the human capital loss per annum from time $t+1$ to $T$. To highlight the relatively different slopes for different education levels, this graph reports the total capital loss with respect to the loss due to having a child at age 22 . We note that higher education levels have higher total human capital losses at each time $t$ relative to the total capital loss at age 22 compared with other education levels. This is because of the relatively steeper falling human capital loss per annum curve.

Combining the total human capital loss with the opportunity cost of parental childcare (plot $d$ ), we produce the narrower definition of the shadow price of a child. Because what is relevant to the marginal rate of inter-temporal substitution is the ratio of the shadow prices, we normalise each education level specific curve to be 100 at age 22 . We see here that the slope declines for each education level. This means that it gets relatively cheaper to have a child later in life. We also notice that the slope is steeper for lower educated. In other words, the cost is lower for lower educated women at younger ages than for higher educated women. 
Figure 3. Components of Shadow Price Calculation of Timing of Birth by Education Level

Source: Author's Calculations

Note: Univ - University Educated; Upsec - Upper Secondary Educated; Losec - Lower Secondary Educated and below.

For Formula for shadow price and components, see equation (13') in text. 
In plot (e) we consider the impact of utilizing a simpler human capital specification as utilized by Walker (1995). Here we see that excluding the impact of decline rates of return to experience and ignoring depreciation effects, we find that the shadow price rises with age, corresponding to the results of Walker's theoretical model. In plot (f), we incorporate the impact of depreciation and see that adding depreciation to the model increases the cost of parental child care on future human capital, reversing the slope observed in plot (e) although less steep than in plot (d). This model therefore corresponds to the finding of Gustafsson et al. (2002) that higher educated women delayed first birth more less educated women. While in the graphs, we considered a gap of one year, the impact of longer periods out of the labor market is to strengthen the direction of these effects.

\section{Empirical Results I - Survival Functions}

In this section we plot the survival functions for different order births. These functions record the average probability of not having a child of a particular birth order at particular ages. In figure 4 , we consider the survival functions of marriage and first births. These functions are estimated over all years of the data, are reported separately for different education levels, and are reported for two different time-scales, age and duration since leaving education.

When we use age as the time scale, we see that at the age of 40 first birth rates are higher for higher education levels, indicating that higher educated women are more likely not to have a child. The graph of the lower educated women is lower than that of the higher educated, indicated that lower educated women have their first child earlier. When we use the duration since leaving education, we see that the duration to first birth although still higher for higher education levels, but that the differential is much less. When utilising the duration since marriage as the time-scale, we look only at the sub-sample who marry. Here we see that the proportion of those with first births after 10 years of marriage is similar across education levels, that the majority of first births occur in the first two to three years of marriage and that although the ordering of durations by education level is the same as for the other duration measures, that differential again is quite small.

The picture for second births is similar, with those with upper secondary and university educations having a very similar pattern. This group have a similar fertility rate after 12 years of marriage to those with lower education levels, but that their births tend to be slightly later. However, although not reported here, most of this delay is due to the delay in having first births with the survival function when duration since last birth is used as the time-scale, the timing differential due to education level becomes much smaller. For third and fourth births fertility rates after 18 years of marriage fall with education levels with again higher education levels have their births slightly later. These differentials remain when we consider duration since last birth as the timescale. 
Figure 4-4. Survival Functions of Not Giving a Birth by Birth Order for (a) Age (b) by Duration Since Leaving Education and (c) Duration Since Marriage by Education Level by Education Level

Source: Author's Calculations

Note: Univ - University Educated; Upsec - Upper Secondary Educated; Losec - Lower Secondary Educated and below. 


\section{Empirical Results II - Cox Proportional Hazard Models}

In this section we report the results of our duration model of fertility by birth order (first, second, third and later births). The models focus on women who ever married, allowing us to consider the impact of being in education on the timing of birth. In Table 5 we describe a set of Cox Proportional Hazard models of first births. The different models utilise different times scales

- $\quad$ Age (All Women and Married Women)

- Duration Since Leaving Education

- Duration Since Marriage

In our proportional hazard model we report $e^{\beta_{i}}$. In other words, a unit change in $x_{i}$ changes the relative hazard by $e^{\beta_{\bar{i}}}$. If the relative hazard is greater than one, then the hazard increases and an event is more likely to occur earlier and if it is less than one an event is more likely to occur later as the hazard is lower.

In the first model, looking at all women, we see that being in education delays the timing of maternity. Higher female wages, due in part to higher education or greater experience, also result in delayed first births. These results support the career-planning hypothesis that women delay having birth while in education or if they have higher potential wages. The relative sign on the female potential wage variable is less than 1 confirming the functional form for human capital accumulation in our theoretical model above that predicts a delay in birth for women with steeper wage trajectories. This result holds in each of the models considered for the timing of first order births.

In our theoretical model, we assume perfect capital markets, in other words, the size of the husband's income will not affect the timing of birth, but only operates through the wealth effect on the number and quality of children. If this hypothesis were true, then the coefficient on husband's earnings would not be significant. The relative hazard for the husband's potential earnings variable is greater than 1 significant at the $90 \%$ level when the time-scale is age. This indicates a positive income effect on the timing of the first birth, so that means that the higher the income of the spouse, the earlier the birth. When we consider the duration since finishing education as the time-scale, the size of this variable is bigger and significant at the $95 \%$ level, however when the duration since marriage is used, the variable becomes insignificant. These results indicate some validity in the income-smoothing hypothesis, but that because the timing of first birth and marriage may be considered joint decisions, income smoothing may influence the timing of birth through the timing of marriage. 
Table 5. Cox Proportional Hazard Model First Birth for Married Women

\begin{tabular}{|c|c|c|c|c|c|c|c|c|}
\hline \multirow[t]{2}{*}{ Duration Variable } & \multicolumn{2}{|c|}{$\begin{array}{l}\text { Age - All } \\
\text { Women }\end{array}$} & \multicolumn{2}{|c|}{$\begin{array}{l}\text { Age - Married } \\
\text { Women }\end{array}$} & \multicolumn{2}{|c|}{$\begin{array}{l}\text { Duration } \\
\text { Since Leaving } \\
\text { Education }\end{array}$} & \multicolumn{2}{|c|}{$\begin{array}{l}\text { Duration } \\
\text { Since } \\
\text { Marriage }\end{array}$} \\
\hline & Coef & $\begin{array}{l}\mathrm{p}- \\
\text { value }\end{array}$ & Coef & $\begin{array}{l}\mathrm{p}- \\
\text { value }\end{array}$ & Coef & $\begin{array}{l}\mathrm{p}- \\
\text { value }\end{array}$ & Coef & $\begin{array}{l}\mathrm{p}- \\
\text { value }\end{array}$ \\
\hline In Education & 0.541 & 0.00 & 1.100 & 0.73 & & & 1.139 & 0.65 \\
\hline Female Wage & 0.972 & 0.00 & 0.955 & 0.00 & 0.981 & 0.00 & 0.986 & 0.00 \\
\hline Husbands Potential Earnings & & & 1.007 & 0.11 & 1.018 & 0.00 & 1.003 & 0.43 \\
\hline Male Unemployment Rate & & & 0.654 & 0.29 & 0.518 & 0.09 & 0.973 & 0.95 \\
\hline Years 1970-1974 (Base) & 1.000 & & 1.000 & & 1.000 & & 1.000 & \\
\hline Years 1975-1979 & 0.568 & 0.00 & 0.279 & 0.00 & 0.469 & 0.00 & 0.981 & 0.84 \\
\hline Years 1980-1984 & 0.328 & 0.00 & 0.088 & 0.00 & 0.261 & 0.00 & 0.792 & 0.05 \\
\hline Years 1985-1989 & 0.197 & 0.00 & 0.027 & 0.00 & 0.136 & 0.00 & 0.818 & 0.15 \\
\hline Years 1990-1994 & 0.123 & 0.00 & 0.009 & 0.00 & 0.074 & 0.00 & 0.696 & 0.03 \\
\hline No. of obs. & 18595 & & 5555 & & 5401 & & 4238 & \\
\hline Log likelihood & -11931 & & -8849 & & -8820 & & -8764 & \\
\hline LR Chi2 & 496 & & 871 & & 426 & & 83 & \\
\hline
\end{tabular}

Source: Author's Calculations based on retrospective data 1970-1994 from the Living in Ireland Survey, 1994.

Note: Education dummies of the father of the mother and cohort dummies are not reported.

We introduce the impact of uncertainty due to unemployment through the use of an age and education level specific male unemployment rate. The relative hazard is less than 1 and is significant for the duration since leaving education time-scale and less so for the age time-scale. It some evidence that if a husband of a particular age and education level faces a higher unemployment rate, they face higher uncertainty and so the couple may delay having children. This variable although significant in terms of duration since leaving education, it becomes insignificant as we move to duration since marriage, indicating that like the impact of male potential income, economic uncertainty may have more influence on the age of marriage rather than on the age of first birth.

One of the biggest differences we see between the models is in the time effects. We see that when we use age or duration since leaving education as the time-scale, the coefficients are significant and decreasing in time, so that the later in the 1970-1994 time period we get the greater the delay in fertility, even when we account for the effect of the other explanatory variables. However in the model for duration since and marriage, the coefficients on the dummies for the period 1975-79 and 1985-89 are not significantly different from the 1970-74 period. This indicates the importance of the changing age of marriage in timing of childbirth.

In Table 6, we consider the timing of later order births, focusing in addition on the time-scale, duration since last birth. For second order births, we see that higher female potential wages delay births with respect to age, confirming the fact that those with a higher opportunity cost of a birth have children later. This is still partially the case for duration since leaving education, however the effect is not significant in terms of duration since marriage, again highlighting the fact that age at marriage captures much of the impact on the timing of births. The variable has a p-value as low as 0.2 for the time-scale duration 
since last birth, but the direction of the effect has changed, indicating that given the time of the first birth, the female wage may have more of an income effect on the timing of the second birth, with the opportunity cost being accounted for by the duration to the first birth. There is some evidence of an income effect due to higher husband's wages resulting in earlier births and at least for duration since education of negative impact of uncertainty due to male unemployment.

For third births, female potential wages again have a significant effect, this time for all time-scales, higher wages resulting in delayed third births. This effect may be due to some degree on the degree of censoring for this population. While most of the population have two births, this birth order exhibits a significant proportion who have no more births. Except for duration since education, the income effect for husband's potential earnings is not significant. Uncertainty due to male unemployment rates however is now highly significant. Not many variables are significant in the model of fourth order births. Women with higher wages on average have fourth order births later, but once one factors in the age of marriage or the timing of the third birth, this effect is not significant. Male earnings are not very significant but however move in the opposite direction to earlier birth orders, capturing the effect observed in O'Donoghue and O'Shea (2003b) that the consumption of child services are a normal good where the income elasticity of quality is higher than quantity and so richer families prefer more quality and so may have less children. There is also some slight evidence of uncertainty having a negative effect on the timing of fourth order births.

\section{Conclusions I}

In O'Donoghue and O'Shea (2003b), we utilised a method to decompose the impact of trends in different variables on the birth rate at different points in time. In this section we decompose the impact of these trends on the timing of birth. Consider the averages of a set of variables at the start of the period (1970-1975), say $\bar{x}_{70}$ and at the end of the period (1990-1994) $\bar{x}_{90}$. The average hazard in the 1970's is therefore

$$
\bar{h}_{70}=h_{0}(t) \exp \left(\sum_{i} \beta_{i} \bar{x}_{70, i}\right)
$$

The proportional change in the average hazard is

$$
\begin{aligned}
& \frac{\bar{h}_{90}}{\bar{h}_{70}}=\frac{h_{0}(t) \exp \left(\sum_{i} \beta_{i} \bar{x}_{90, i}\right)}{h_{0}(t) \exp \left(\sum_{i} \beta_{i} \bar{x}_{70, i}\right)}=\frac{\exp \left(\sum_{i} \beta_{i} \bar{x}_{90, i}\right)}{\exp \left(\sum_{i} \beta_{i} \bar{x}_{70, i}\right)} \\
& =\exp \left(\sum_{i} \beta_{i} \bar{x}_{90, i}-\sum_{i} \beta_{i} \bar{x}_{70, i}\right)
\end{aligned}
$$

This implies 


$$
\ln \left(\frac{\bar{h}_{90}}{\bar{h}_{70}}\right)=\sum_{i} \beta_{i}\left(\bar{x}_{90, i}-\bar{x}_{70, i}\right)
$$

which in turn by dividing produces our decomposition index that sums to 100 :

$$
100=\sum_{i} \frac{\beta_{i}\left(\bar{x}_{90, i}-\bar{x}_{70, i}\right)}{\ln \left(\bar{h}_{90} / \bar{h}_{70}\right)} \times 100
$$

In Table 7, we report the decomposition for one time-scale, duration since leaving education, comparing the period 1970-74 with the period 1990-94. The results however are reasonably robust to this decision. Most of the change over this period can be explained by period and cohort specific effects. The impact of the opportunity cost of having a child as proxied by the potential female wage, is the next most important effect, having a lower effect on later order births. Higher wages over time have resulted in later births. The next most important is the impact of uncertainty. Higher unemployment rates for males result in later births and for later order births this is more important than the opportunity cost of having a child. Finally although the effect is quite small, increasing male income has pushed timing in the other direction, with those with higher wages having earlier births.

\section{Conclusions II}

In this paper, we extended the model of Walker (1995) to incorporate the career-planning hypothesis that results in higher educated women delaying having children. We utilized data from the 1994 Living in Ireland Survey to quantify using Survival Analysis, the timing of maternity in Ireland over the period 1990-1994. The principle conclusion was that the career-planning hypothesis was supported as being in education and higher potential earnings had impact of delaying births. There was also some evidence that higher male unemployment rates resulted in delayed births as well as evidence of an income effect due to male earnings, indicating some support for the consumption smoothing hypothesis. While there is an upward trend in duration to first birth, the timing of marriage, once economic variables are considered, accounts for much of this secular trend, indicating that changes in the age of marriage has had a significant impact on the timing of first order births.

In the period since 1994, there has been some recovery in the birth rate. The age at first birth however has continued to rise. It would be interesting therefore to use later data to assess the impact of the forces, particularly the income effect due to the high economic growth of the period and the reduced uncertainty due to lower unemployment rates and increased opportunity costs due to higher female participation rates, that have influenced these events. 
Table 6. Cox Proportional Hazard Model of Second, Third and Fourth Births for Married Women

\begin{tabular}{|c|c|c|c|c|c|c|c|c|c|c|c|c|c|c|c|c|}
\hline \multirow{3}{*}{ Duration Var. } & \multicolumn{8}{|c|}{ Second Birth } & \multicolumn{8}{|c|}{ Third Birth } \\
\hline & Age & & Educ. & & Marr & & Birth & & Age & & Educ. & & Marr & & Birth & \\
\hline & Coef & p-value & Coef & p-value & Coef & p-value & Coef & p-value & Coef & p-value & Coef & p-value & Coef & p-value & Coef & p-value \\
\hline In Education & 1.546 & 0.15 & & & 0.892 & 0.71 & 0.857 & 0.62 & 1.655 & 0.23 & & & 1.293 & 0.54 & 1.614 & 0.25 \\
\hline Husbands Potential Earnings & 1.006 & 0.15 & 1.017 & 0.00 & 1.005 & 0.28 & 1.007 & 0.11 & 0.998 & 0.76 & 1.008 & 0.13 & 0.999 & 0.84 & 0.999 & 0.81 \\
\hline Male Unemployment Rate & 0.725 & 0.45 & 0.420 & 0.18 & 0.796 & 0.35 & 0.598 & 0.25 & 0.195 & 0.00 & 0.136 & 0.00 & 0.363 & 0.07 & 0.309 & 0.03 \\
\hline Years 1970-1974 (Base) & 1.000 & & 1.000 & & 1.000 & & 1.000 & & 1.000 & & 1.000 & & 1.000 & & 1.000 & \\
\hline Years 1975-1979 & 0.293 & 0.00 & 0.486 & 0.05 & 0.811 & 0.08 & 0.876 & 0.08 & 0.342 & 0.00 & 0.569 & 0.00 & 0.841 & 0.11 & 0.928 & 0.48 \\
\hline Years 1985-1989 & 0.014 & 0.00 & 0.074 & 0.01 & 0.417 & 0.06 & 0.476 & 0.07 & 0.019 & 0.00 & 0.079 & 0.00 & 0.388 & 0.00 & 0.476 & 0.00 \\
\hline Years 1990-1994 & 0.004 & 0.00 & 0.034 & 0.01 & 0.359 & 0.06 & 0.478 & 0.08 & 0.006 & 0.00 & 0.040 & 0.00 & 0.363 & 0.00 & 0.479 & 0.00 \\
\hline No. of obs. & 4713 & & 4625 & & 4665 & & 4713 & & 7082 & & 7006 & & 7073 & & 7082 & \\
\hline Log likelihood & -8672 & & -870 & & -9166 & & -9303 & & -666 & & -66360 & & -6903 & & -6939 & \\
\hline LR Chi2 & 1056 & & 575 & & 123 & & 79 & & 685 & & 434 & & 138 & & 97 & \\
\hline
\end{tabular}

Source: Author's Calculations based on retrospective data 1970-1994 from the Living in Ireland Survey, 1994.

Note: Education dummies of the father of the mother and cohort dummies are not reported. 


\begin{tabular}{|c|c|c|c|c|c|c|c|c|}
\hline \multirow{3}{*}{ Duration Var. } & \multicolumn{8}{|c|}{ Fourth Birth } \\
\hline & Age & & Educ. & & Marr & & Birth & \\
\hline & Coef & p-value & Coef & p-value & Coef & p-value & Coef & p-value \\
\hline In Education & 1.226 & 0.84 & & & 1.892 & 0.53 & 2.767 & 0.32 \\
\hline Female Wage & 0.983 & 0.00 & 0.991 & 0.10 & 1.000 & 0.98 & 1.001 & 0.79 \\
\hline $\begin{array}{l}\text { Husbands Potential } \\
\text { Earnings }\end{array}$ & 0.994 & 0.35 & 1.000 & 0.98 & 0.993 & 0.29 & 0.993 & 0.25 \\
\hline Male Unemployment Rate & 0.507 & 0.32 & 0.284 & 0.07 & 0.606 & 0.47 & 0.512 & 0.33 \\
\hline Years 1970-1974 & 1.000 & & 1.000 & & 1.000 & & 1.000 & \\
\hline Years 1975-1979 (Base) & 4.117 & 0.00 & 0.382 & 0.00 & 0.532 & 0.00 & 1.548 & 0.00 \\
\hline Years 1980-1984 & 0.288 & 0.00 & 0.174 & 0.00 & 0.332 & 0.00 & 0.680 & 0.00 \\
\hline Years 1985-1989 & 0.063 & 0.00 & 0.060 & 0.00 & 0.177 & 0.00 & 0.349 & 0.00 \\
\hline Years 1990-1994 & 0.013 & 0.00 & 0.021 & 0.00 & 0.097 & 0.00 & 0.233 & 0.00 \\
\hline No. of obs. & 5902 & & 5870 & & 5897 & & 5902 & \\
\hline Log likelihood & -398 & & -39851 & & -4089 & & -4098 & \\
\hline LR Chi2 & 408 & & 273 & & 150 & & 129 & \\
\hline
\end{tabular}

Source: Author's Calculations based on retrospective data 1970-1994 from the Living in Ireland Survey, 1994.

Note: Education dummies of the father of the mother and cohort dummies are not reported.

\section{Table 7: Decomposition of Percentage change in Average Hazard of Maternity by Birth Order 1970-74 to 1990-94}

\begin{tabular}{lllll}
\hline Birth Order & 1 & 2 & 3 & 4 \\
\hline Female Wage & 17.2 & 3.8 & 4.5 & 2.4 \\
Male Earnings & -3.8 & -0.7 & -2.2 & 0.0 \\
Male Unemployment Rate & 8.8 & 14.8 & 25.0 & 20.0 \\
Time (Year and Cohort) & 77.8 & 82.1 & 72.8 & 77.6 \\
Total & 100.0 & 100.0 & 100.0 & 100.0 \\
& & & & \\
Ave. Dur. Since Leaving Ed. for Population in 1970-74 & 8.7 & 10.7 & 13.1 & 14.7 \\
Ave. Dur. Since Leaving Ed. for Population in 1990-94 & 11.8 & 13.9 & 17.0 & 19.8 \\
Ave. Dur. Since Leaving Ed. for those with births in 1970-74 & 8.3 & 10.1 & 12.5 & 14.2 \\
Ave. Dur. Since Leaving Ed. for those with births in 1990-94 & 10.6 & 12.8 & 14.9 & 15.6 \\
\hline
\end{tabular}

Source: Author's Calculations based on retrospective data 1970-1994 from the Living in Ireland Survey, 1994.

Notes:

1. The hazard is calculated for average characteristics in the period 1970-74 and the period 1990-94. Each row represents the change in the contribution to the change average value of the variable to the change in the average hazard rate.

2. The time-scale used is duration since leaving education. 


\section{ACKNOWLEDGEMENT}

This paper is based upon empirical analyses carried out by Cathal O'Donoghue as part of his PhD at the London School of Economics, forming work underlying the fertility module of his Life-cycle Income Analysis Model (LIAM). He gratefully acknowledges financial assistance from the Postgraduate Fellowship of the Economic and Social Research Institute, Dublin. This paper was partially written while Cathal O'Donoghue was a SAGE Visiting Fellow at the London School of Economics and an ICER fellow at the University of Turin. He gratefully acknowledges the hospitality provided. The paper uses data from the 1994 Living in Ireland Survey, made available by the Economic and Social Research Institute, Dublin. We have benefited from comments from seminar participants in Galway and at SCHOLAR in Amsterdam and in particular Siv Gustafsson and Cecile Wetzels. The authors are responsible for all remaining errors.

\section{NOTES}

1. We do not incorporate here the "rebound" effect of human capital appreciating more rapidly for a while after re-entering the labor market (See Montgomery and Trussell, 1986 and Mincer and Ofek, 1982).

2. See Walker (1995) for a more detailed discussion of the properties of this relation.

3. Given the limited child related social policies pursued in Ireland, we ignore the impact of public policy in the definition of our budget constraint.

4. See O'Donoghue and O'Shea (1993) for a description of this process. Checks were considered to assess the degree of bias introduced by the different samples. In O'Donoghue and O'Shea we find that results are robust to this process.

5. Further observations are available for the years before marriage. These are not reported here. 


\section{References}

Ahn N., and P., Mira. 2001. Job, bust, baby bust: the Spanish case, Journal of Population Economics, Vol. 14: 505-521.

Ahn N., and P., Mira. 1999. A note on the Changing relationship between Fertility and Female Employment Rates in Developed Countries, Documento de Trabajo 99-09, FEDEA, Spain.

Becker, G. 1960. An Economic Analysis of Fertility. In Demographic and Economic Change in Developed Countries. Universities National Bureau Conference Series 11. Princeton N.J.: Princeton University Press.

Becker, G. and H. Lewis. 1973. On the interaction between the Quantity and Quality of Children, Journal of Political Economy, Vol. 81: S279-S288.

Bettio, F. and P. Villa. 1998. A Mediterranean perspective on the breakdown of the relationship between female participation and fertility, Cambridge Journal of Economics, Vol. 22: 137-171.

Cigno, A. 1991. Economics of the Family. Clarendon Press, Oxford.

Coleman, D.A. 1992. The Demographic Transition in Ireland in International Context. In Goldthorpe, J. and C. Whelan (eds.), The Development of Industrial Society in Ireland, Proceedings of the British Academy, Vol. 79. London: British Academy.

Del Bono, E. 2001. Estimating Fertility Responses to Expectations: Evidence from the 1958 British Cohort. Paper presented to the Conference of the European Society of Population Economics, Athens, June.

Easterlin, R. A. 1980. Birth and Fortune: The Impact of Numbers on Personal Welfare. Chicago: University of Chicago Press.

Eurostat 2002. European Social Statistics: Demography. Luxembourg: Eurostat.

Gustafsson S. 2001. Optimal age at motherhood. Theoretical and empirical considerations on postponement of maternity in Europe, Journal of Population Economics, Vol. 14: 225-247.

Gustafsson S., E. Kenjoh, C. Wetzels. 2002. The Role of Education in Postponement of Maternity in Britain, Germany, the Netherlands and Sweden. In E. Ruspini and A. Dale (eds.), The Gender Dimension of Social Change: The Contribution of Dynamic Research to the Study of Women's Life Courses. Bristol: The Policy Press.

Happel, S.K., J.K. Hill and S.A. Low. 1994. An Economic Analysis of the Timing of Childbirth, Population Studies, Vol. 38: 299-311.

Heckman, J. 1979. Sample selection bias as a specification error, Econometrica, Vol. 47: 153-161.

Heckman J. and J. Walker. 1990. The Relationship between Wages and Income and the Timing and Spacing of Births: evidence from Swedish Longitudinal Data, Econometrica, Vol. 58: 1411-1441.

Hotz V., Klerman, J. and R. Willis. 1997. The Economics of Fertility in Developed Countries. In Rosensweig, M and O. Stark (eds.), Handbook of Population and Family Economics, pp. 275-347. 
Hotz V. and R. Miller. 1988. An Empirical Analysis of Life Cycle Fertility and Female Labor Supply, Econometrica, Vol. 56: 91-118.

Hynes S. and C. O'Donoghue. 2003. Permanent and Transitory Earnings Inequality in Ireland 1994-1999, NUIG Working Paper.

Kalbfleisch, J.D. and R.L. Prentice. 1980. The Statistical Analysis of Failure Time Data. New York: John Wiley and Sons.

Kohler, Hans-Peter, Francesco C. Billari and José Antonio Ortega. 2002. The Emergence of Lowest-Low Fertility in Europe During the 1990s. Population and Development Review 28: 641-680.

Mincer J., and H. Ofek. 1982. Interrupted Work Careers, Journal of Human Resources, Vol.17: 3-24.

Montgomery, M. and J. Trussell, 1986. Models of Marital Status and Childbearing. In O. Ashenfelter and R. Layard (eds.), Handbook of Labor Economics, Volume I. Amsterdam: Elsevier Science Publishers.

O'Donoghue C. 2002. Redistribution over the Lifetime in the Irish Tax-Benefit System: An Application of a Prototype Dynamic Microsimulation Model for Ireland, Economic and Social Review, Vol. 32.

O'Donoghue C. and E. O'Shea, 2003a, Explaining the Fertility Decline in Ireland, Department of Economics Working Paper, National University of Ireland Galway.

O'Donoghue C. and E. O'Shea, 2003b, Decomposing the Impact of Increased Education Levels on the Fertility Decline in Ireland, Department of Economics Working Paper, National University of Ireland Galway.

Walker, J.R. 1995. The Effect of Public Policies on Recent Swedish Fertility Behaviour, Journal of Population Economics, Vol. 8: 223-251.

Willis J. 1973. A New Approach to the Economic Theory of Fertility Behaviour, Journal of Political Economy, Vol. 81: S14-S64. 


\section{FIGURES}

Figure 4-1 Age-Specific Fertility Rate 1965-94

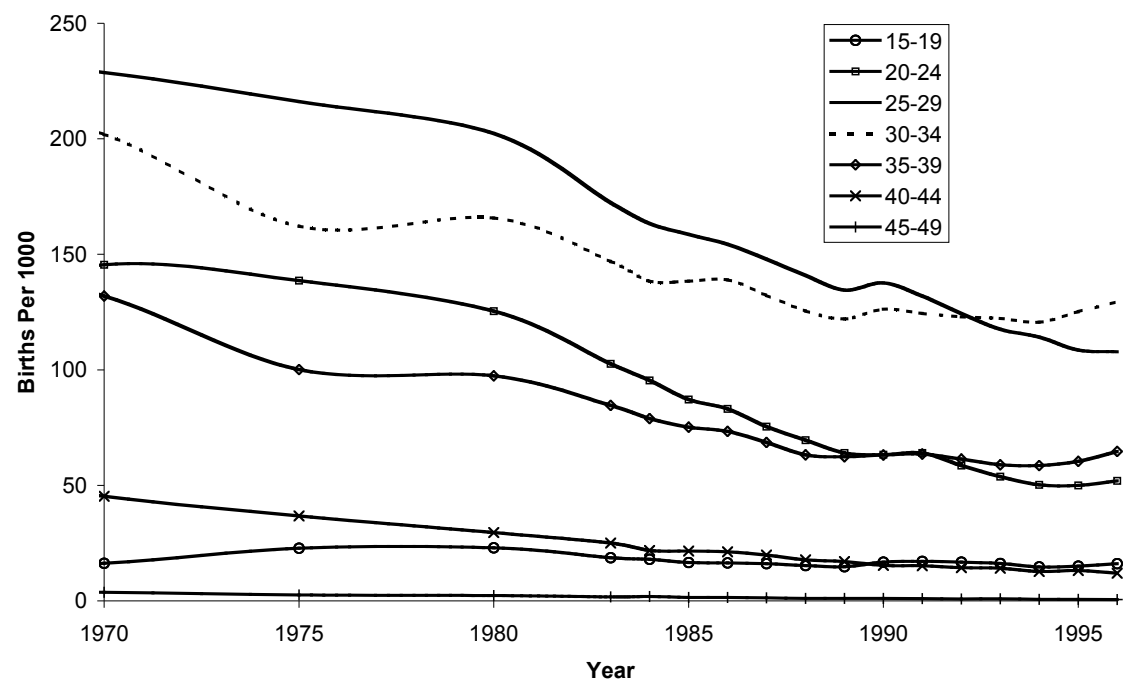

Source: Recent Demographic Developments in Europe, Council of Europe (1997). 
Figure 4-2. Mean Age at Birth, Education Level and Labor Force Characteristics in Ireland, 19702001

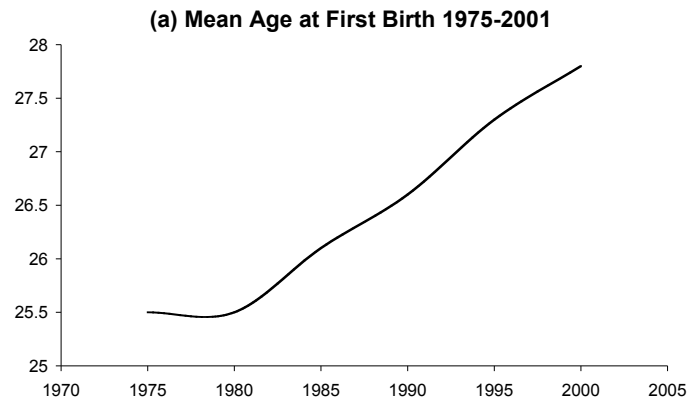

(c) Male Unemployment Rate 1971-2001

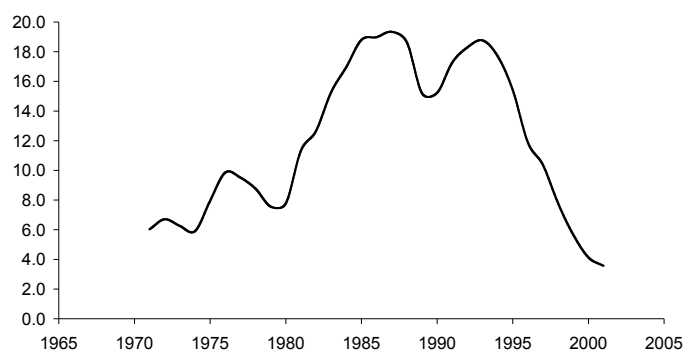

(b) Education Level of Women 1970-1994

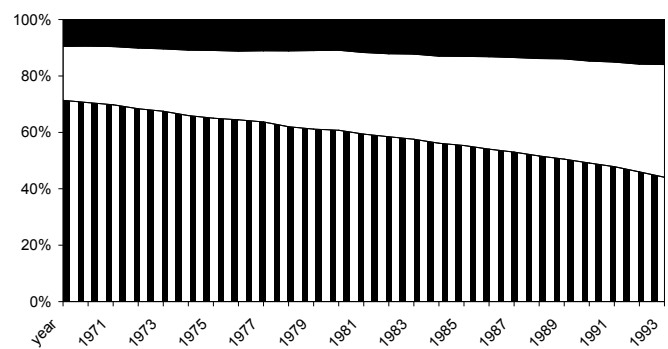

(d) Female Labour Participation Rate 1971-2001

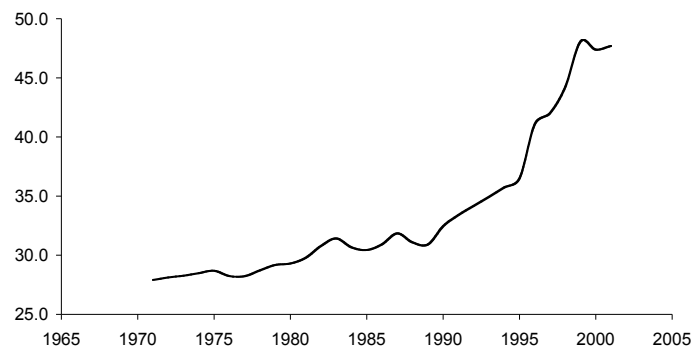

Sources: European Social Statistics: Demography (Eurostat, 2002); Author's Calculations;.and (d) Statistical Yearbook (CSO: 1975-1997), The Trend of Employment and Unemployment (CSO: 19791988), Statistical Bulletin (CSO: 1979-2002), Labour Force Survey (CSO: 1979-2001). 
Figure 3: Components of Shadow Price Calculation of Timing of Birth by Education Level

(a) Earnings Profiles - Opporunity Cost of Parental Childcare (LoSec at age $16=100$ )

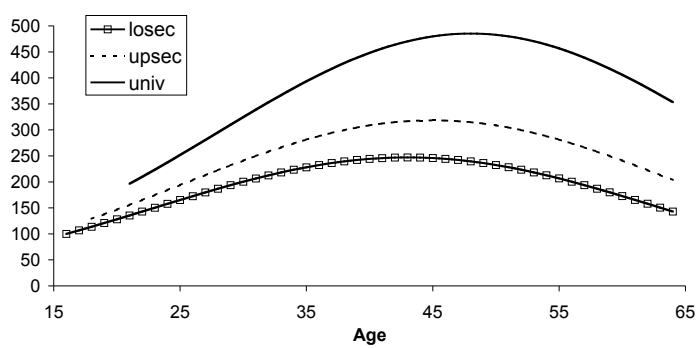

(d) Shadow Price (Age $22=100)$ - With Quadratic Experience Term, With Depreciation

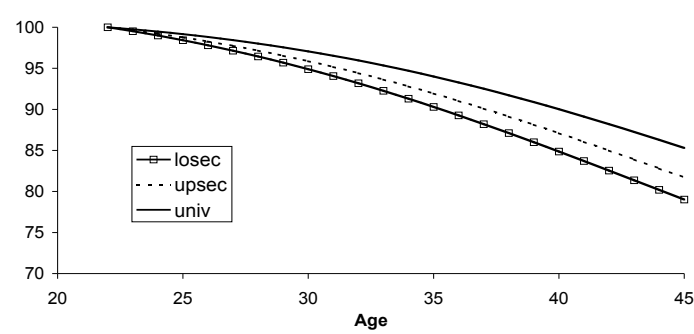

(b) Human Capital Loss p.a. (LoSec, Age $22=100)$

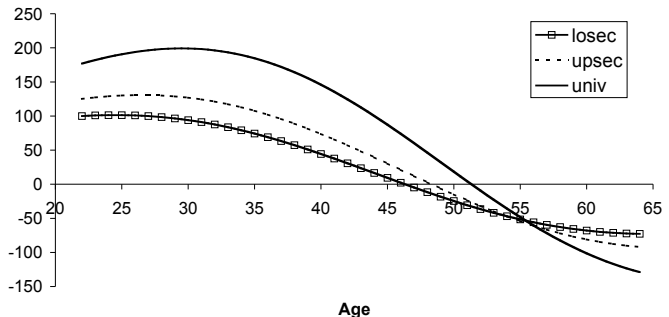

(e) Shadow Price (Age $22=100)$ - No Quadratic Experience Term, No Depreciation

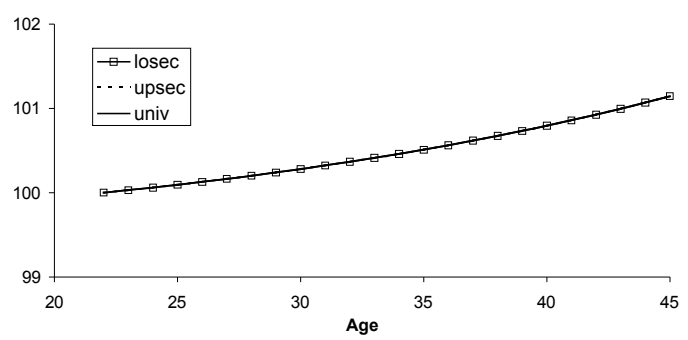

Source: Author's Calculations. Note: Univ - University Educated; Upsec - Upper Secondary Educated; Losec - Lower Secondary Educated and below. For Formula for shadow price and components, see equation (13') in text. 
Figure 4. Survival Functions of Not Giving a Birth by Birth Order for for (a) Age (b) by Duration Since Leaving Education and (c) Duration Since Marriage by Education Level by Education Level
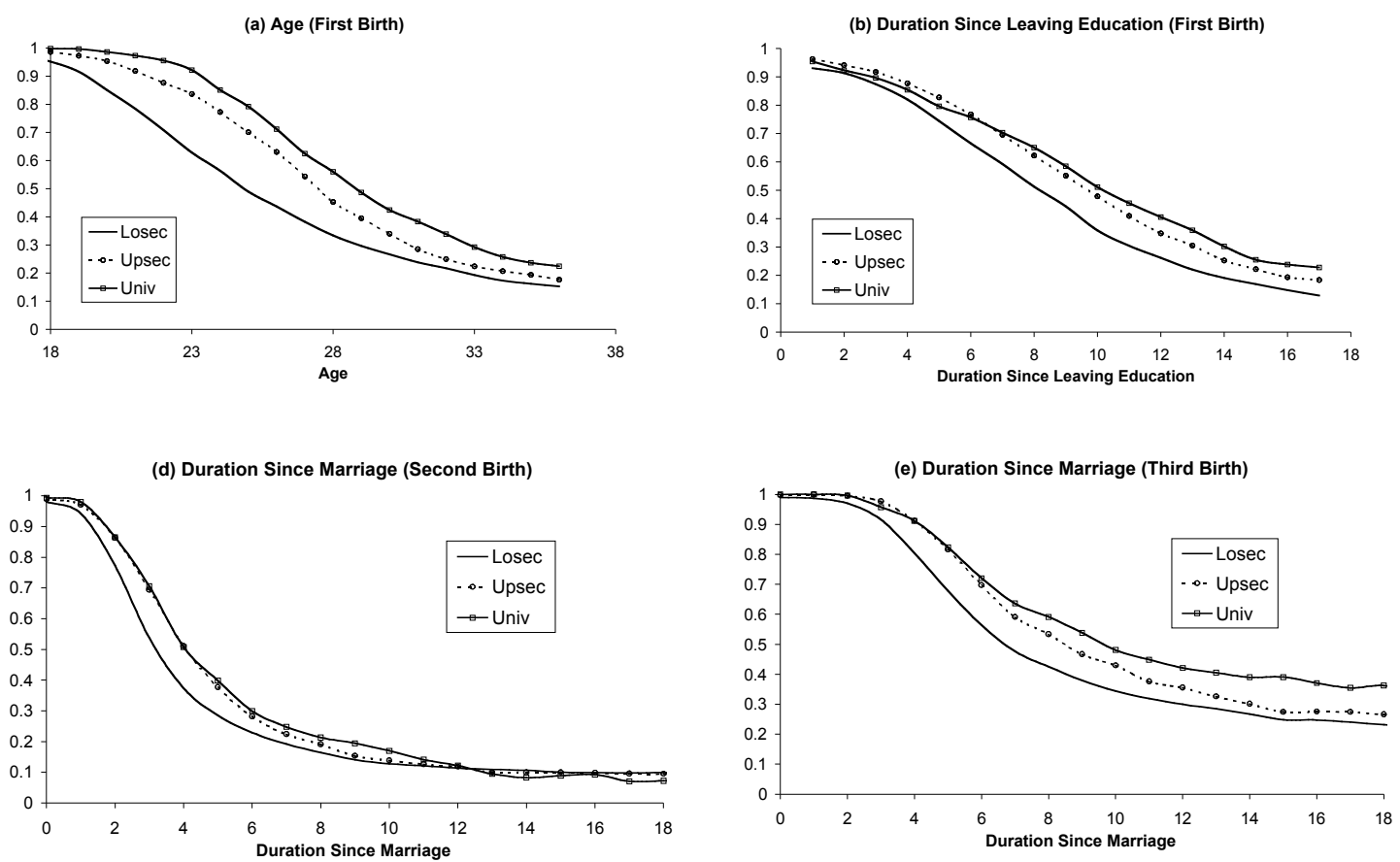

Source: Author's Calculations. Note: Univ - University Educated; Upsec - Upper Secondary Educated; Losec - Lower Secondary Educated and below. 